from consultant colleagues? We do not know because we do not have all the facts. Under the 30 years rule the secretary of state for health has made it hard to get them.

PVSCOTT

Alexandra Hospital,

Redditch,

Worcestershire B98 7UB

1 Mister Hyde. Poor relation. World Medicine 1984;19(23):48

2 Smith R. Whistle blowing: a curse on ineffective organisation $B M \mathcal{F}$ 1992;305:1308-9. (28 November.)

Dyer C. RHA told to reinstate "redundant" Helen Zeitlin. BMF 1992;305:1177. (14 November.)

4 Warden J. Speaking out in the NHS. BMF 1992;305:1180. (14 November.)

5 Greene D, Cooper J. Whistle blowers. BMf 1992;305:1343-4. (28 November.)

EDITOR,-Going public necessitates taking the rough with the smooth, but the BMF's account of my reinstatement is unjust. ${ }^{\prime}$ Clare Dyer was not present at the two day public hearing last August. Had she been she would have known that the 20 complaints she alludes to as fact were wholly unsubstantiated and, indeed, had not even materialised. They were the claims of one colleague who was also making allegations concerning my mental health.

The number of reports of health care professionals being silenced, threatened, or dismissed is growing, and common characteristics of these cases are emerging. They include abuse of power, character assassination, and, sadly, colluding colleagues acting out of personal antagonism, jealousy, or a derisive self interest.

HELEN ZEITLIN

Bidford on Avon,

Warwickshire B50 4BU

1 Dyer C. RHA told to reinstate "redundant" Helen Zeitlin. BMF 1992;305:1177. (14 November.)

EdrToR,-Dr Helen Zeitlin's unwarranted and peremptory dismissal, now reversed on appeal,' was a disturbing example of the "macho" style of NHS management condemned by Jenny Simpson and Richard Smith. ${ }^{2}$ That this approach to management is becoming increasingly common is exemplified by the rapid rise in the number of proved charges of breaches of the nursing code by "abuse of management authority" by nurse managers which have been the subject of disciplinary action by the United Kingdom Central Council for Nursing in recent years: 34 in 1991-2 compared with 14 and five in the two preceding years.

Dyer observes that the government's whistleblower's charter provides no protection for NHS employees who go public after failing to obtain satisfaction through the internal complaints procedure. Zeitlin herself has stated that whistleblowers are often disciplined or dismissed (as she was) on "trumped up charges of professional misconduct or alleged redundancy" rather than whistleblowing. ${ }^{4}$

Victims of such action by nurse or doctor managers may obtain redress through their professional code of conduct and disciplinary procedure. No such action, however, is possible against managers who are not members of the caring professions because they are not subject to any such ethical code.

There is surely now a need for a code of conduct making all NHS managers accountable, through an independent disciplinary procedure, should they introduce measures that place patients at risk or attempt to suppress reasonable public criticism of such measures by doctors and nurses. I advocated such a code last year, ${ }^{5}$ since when the proposal has featured in the Liberal Democrats' policy document Restoring the Nation's Health'; support has come from the Hospital Doctors' Association'; and David Picking, the national officer of the Confederation of Health Service Employees, proposed such a code at a meeting of the International Labour Organisation. ${ }^{8}$ I hope that the BMA will follow suit.

Ripponden,

R F HEYS

West Yorkshire HX6 4EX

1 Dyer C. RHA told to reinstate "redundant" Helen Zeitlin. $B M \mathcal{F}$ 1992;305:1177. (14 November.)

2 Simpson J, Smith R. "Macho" management in the NHS. BMI 1992;304:1586. (20 June.)

3 Mason P. Misused authority. Nursing Times 1992;88(40):19.

4 Zeitlin H. The sounds of silence. Guardian 1992 Oct 22:20.

5 Heys RF. Code of conduct needed to keep managers in line. Hospital Doctor 1991 Dec 5:28.

6 Liberal Democrat Party. Restoring the nation's health: managing health services. London: Liberal Democrat Publications, 1992:15

Wrede D. Code vital to keep managers in check. Hospital Doctor 1992 Jan 16:13

Managers should have a conduct code. Nursing Times 1992; 88(40): 6 .

\section{Postmenopausal hormone replacement therapy}

EDITOR,-In their regular review on postmenopausal hormone replacement therapy H S Jacobs and $\mathrm{F}$ E Loeffler quote the minimum bone sparing dose of oestrogens as $2 \mathrm{mg}$ oestradiol valerate, $50 \mu \mathrm{g}$ transdermal oestrogen, and $0.625 \mathrm{mg}$ conjugated oestrogen. ${ }^{1}$ During a review of prescribing of hormone replacement therapy in South Glamorgan we were surprised to find that 808 $(37 \%)$ of 2170 patients receiving oestradiol valerate or unopposed transdermal oestrogens were receiving suboptimal doses for bone sparing (that is, $1 \mathrm{mg}$ oestradiol valerate or $25 \mu \mathrm{g}$ transdermal oestrogens)

Though a low dose of oestrogen is needed in a few patients because of initial adverse effects, most patients can tolerate the standard doses without difficulty. Doctors should be aware that some preparations used in hormone replacement therapy contain suboptimal doses of oestrogens to prevent osteoporosis.

D CLEMENTS R SALTER

Llandough Hospital

Penarth,

South Glamorgan CF6 1 XX

1 Jacobs HS, I oeffler FE. Postmenopausal hormone replacement therapy. $B M 7$ 1992;305:1403-8. (5 December.)

\section{Managing urinary tract infection}

EDrTOR,-Martin E Wilkie and colleagues highlight the importance of screening for bacteriuria in patients at high risk of urinary tract infections, such as pregnant women.' Other groups at high risk include those attending urological and renal clinics, who may also benefit from such screening. Surprisingly, Wilkie and colleagues do not mention the value of the physical appearance of urine in the management of urinary tract infection. A simple method of excluding urinary tract infection is to assess visually the clarity (irrespective of colour) of a freshly passed specimen of urine.

The clarity or turbidity of 363 samples of urine collected from patients attending two adult nephrology clinics over six months was compared with a dipslide culture obtained from the same samples. The predictive value of a negative result (clarity) was $97 \%$ and the false negative rate $3 \%$, enabling this simple examination to be used as an exclusion test for further testing. ${ }^{2}$ The crimped aluminium bowl used to collect samples made assessing clarity easier. Similar high predictive values for a negative result (clarity) with low false negative rates have been shown in paediatric nephrology clinics ${ }^{3}$ and adult internal medicine clinics

Urine culture results in a considerable workload for many clinical bacteriology laboratories; samples may be taken without proper precautions to avoid contamination, and there may be delays in transporting samples from the clinics to the laboratory. Analysis of only those samples assessed as cloudy could result in considerable financial savings as well as reduce the workload of clinics. Physical inspection of urine should be part of the diagnostic work up for urinary tract disorders even when high tech diagnostic facilities are available.

I H KHAN

Department of Medicine and Therapeutics,

University of Aberdeen,

Aberdeen AB9 2ZD

1 Wilkie ME, Almond MK, Marsh FP. Diagnosis and managemen of urinary tract infection in adults. BMF 1992;305:1137-41 (7 November.)

2 Phillips G, Fleming LW, Khan I, Stewart WK. Urine transparency as an index of absence of infection. $\mathrm{Br} f$ Urol 1992;70:191-5.

3 Rawal K, Senguttuvan P, Morris M, Chantler C, Simmons NA. Significance of crystal clear urine. Lancet 1990;335:1228.

Pouchot J, Launay I, Cahen P, Boussougant Y, Vinceneux P.

Significance of crystal clear urine. Lancet 1990;336:320-1.

EDITOR,-We are alarmed at the primacy that Martin E Wilkie and colleagues give to intravenous urography in the investigation of adults with urinary tract infection.' Their prominent box of indications for the procedure's use is without qualification or guidance and, like the radiology section of the review, is merely an unhelpful list which fails to reflect recent developments in the imaging of adults with urinary tract infection. Their indications are at variance with the guidelines of the Royal College of Radiologists. ${ }^{2}$

The two groups of adults most commonly affected by urinary tract infection are elderly men and young women. In elderly men infection usually occurs in the context of bladder outflow obstruction, for which ultrasonography and plain abdominal radiography are preferred to intravenous urography. ${ }^{2-4}$ For young women there are strong reasons to avoid exposure to ionising radiation, particularly in view of urography's low yield of abnormalities affecting management. ${ }^{5-7}$

Ultrasonography has a far greater role than merely for "the detection and percutaneous drainage of hydronephrosis." It provides a safe and accurate alternative to urography in investigating most adults with urinary tract infection and, combined with plain abdominal radiography, should be the first line of radiological investigation for the vast majority. The results of our prospective blinded comparison of the two techniques in a wide range of adults referred from general practice and outpatient clinics showed their relative merits. ${ }^{8} \mathrm{~A}$ small proportion of patients will still require urography, and we concede the difficulty in detecting papillary necrosis in patients with systemic disease with ultrasonography. All of Wilkie and colleagues' other indications for urography were satisfactorily shown by ultrasonography and plain radiography in our series. ${ }^{8}$ We challenge the notion that haematuria, particularly microscopic, in proved urinary tract infection warrants intravenous urography.

Plain radiography and ultrasonography gave satisfactory images in all our patients whose infection was complicated by haematuria.

Nephrologists see only a minority of adults with urinary tract infection, and it is perhaps not surprising that the only ultrasonographic images in Wilkie and colleagues' article are of transplanted kidneys. In our practice almost three quarters of patients are referred for radiological study by general practitioners, who manage most episodes of infection. Imaging strategies should reflect this, and articles proffering guidance on the use of radiology must do better than merely give a list of 